\title{
Intercostal Muscle Flap in Post Tuberculous Pneumonectomy: A New Technique
}

\author{
Alaa Brik, Abdel-Maged Salem, Osama Saber \\ Department of Cardiothoracic surgery, Zagazig University Hospital, Zagazig, Egypt \\ Email: alaabrik@yahoo.com
}

Received February 13, 2012; revised March 26, 2012; accepted April 17, 2012

\begin{abstract}
Objective: There are many risk factors for postoperative bronchopleural fistula (BPF), including extensive resection, diabetes, chronic infection, perioperative steroid therapy, preoperative chemotherapy, and radiotherapy, the risk of bronchopleural fistula increases with resection for inflammatory diseases, especially Mycobacterium tuberculosis (MTB). The aim of this study is to evaluate the efficacy and safety of using double pedicled intercostal muscle flaps with dual blood supply to buttress the bronchial stump after pneumonectomy for tuberculous lesions as a prophylactic new technique from post-pneumonectomy BPF. Methods: Between 2007 to 2011, 47 patients with pneumonectomy for post tuberculous lesions in the department of cardiothoracic surgery, Zagazig University Hospital were divided into two groups. Group A: 28 patients with single pedicled intercostal muscle flap used and applied on the bronchial stump after pneumonectomy. Group B: 19 patients with double pedicled intercostal muscle flaps used and applied on the bronchial stump. The mean age of the patients was 42.9 years (range 27 - 67 years) in Group A, 44.8 years (range 36 - 71 years) in Group B. Results: Bleeding in one patient in Group A (3.5\%) and two patients in Group B (10.5\%); empyema in two patients $(7.1 \%)$ in Group A only one of them developed bronchopleural fistula; arrhythmias in one patients $(3.5 \%)$ in Group A and one patient in Group B (5.2\%); chylothorax in one patients (3.5\%); Chronic chest pain in one patient in Group A (3.5\%) and two patients in Group B (10.5\%). The mean follow up period was $32.7 \pm 12.9$ months (range between 3 and 48 months). All patients remained symptom free with no evidence of late bronchopleural fistula in Group B. Conclusions: Double pedicled intercostal muscle flaps with dual blood supply buttressing the bronchial stump is new prophylactic technique from BPF after pneumonectomy for pulmonary tuberculous lesions in high risk patients.
\end{abstract}

Keywords: Intercostal Muscles; Pneumonectomy; Tuberculosis

\section{Introduction}

Bronchopleural fistula after pneumonectomy remains a serious complication. There are many risk factors for bronchopleural fistula, which include extensive resection, diabetes, chronic infection, perioperative steroid therapy, preoperative chemotherapy, and radiotherapy [1-3]. Pulmonary resection for chronic infection remains a common procedure in the Middle East [4]. Tuberculosis continues to account for the majority of these cases [5]. The risk of BPF increase with resection for inflammatory diseases, especially Mycobacterium Tuberculosis (MTB) [6]. We have used double pedicled intercostal muscle flaps (DPICM), one with its blood supply from anterior intercostal vessels and the other with its blood supply from posterior intercostal vessels to buttress the bronchial stumps in patients undergoing post tuberculous pneumonectomy. In this prospective study, we evaluate this novel procedure with particular reference to the incidence of postoperative bronchopleural fistula.

\section{Patients and Methods}

\subsection{Patients Characteristic}

The study was conducted between 2007 to 2011, Department of Cardiothoracic surgery, Zagazig University Hospital. 47 patients with pneumonectomy for post tuberculous lesions were divided into two groups. Group A: 28 patients with single pedicled intercostal muscle flap used and applied on the bronchial stump after pneumonectomy with its posterior intercostal blood supply. Group B: 19 patients with double pedicled intercostal muscle flaps used and applied on the bronchial stump after pneumonectomy with dual blood supply one with anterior intercostal blood supply and the other with posterior intercostal blood supply. Patients with previous BPF after pneumonectomy were excluded. The mean age of the patients was 42.9 years (range 27 - 67 years) in Group A, 44.8 years (range 36 - 71 years) in Group B, The characteristics and risk factors of the two groups are shown in Table 1. The follow-up periods ranged from 3 to 48 
months after surgery.

\subsection{Pre-Operative Assessment}

Standard chest radiographs (CXR), pulmonary function tests (PFT's), blood gas analysis and computerized axial tomography (CT scan) were used in all to determine the extent of disease, and the ability of the patients to withstand the surgery.

\subsection{Surgical Technique}

The intercostal muscle (ICM) flap is easily harvested. The flap must be harvested before placing a rib spreader. The intercostal muscle and neurovascular pedicle are separated from the inferior aspect of corresponding rib using a periosteal elevator. The ICM is then freed from the underside of the superior rib taking great care to preserve the intercostal neurovascular bundle, the elevator is preferred over cautery to avoid thermal injury to the pedicle but we used both of them.

The intercostal muscle flap was harvested in the fifth intercostal space in cases of single muscle flap which was cut at its anterior edge with posterior intercostal blood supply, however when we used double intercostal muscles we harvest the muscles in the fifth and fourth space and the 5th rib was resected Figure 1, the upper intercostal muscle was cut at its anterior end and the lower intercostal muscle was cut at its posterior end. We wrap the flap in moist, warm gauze. We performed this procedure using cautery and periosteal elevator. All bronchial stump closure was performed with interupted sutures 3 zero vicryl and tested for air leak. The single pedicle intercostal muscle flap was attached over the two edges of bronchial stump while in double pedicle intercostal muscle flap each muscle attached to one edge of the bronchial Stump Figure 2. Following pneumonectomy, Assessment of muscle flap viability may be performed at this point; care should be taken to avoid torsion of the flap.

\subsection{Statistical Analysis}

Results were analyzed using SPSS version 15.0 (Statistical Package for Social Science, SPSS Inc., Chicago, IL, USA). Continuous variables, such as age were expressed as the mean \pm S.D. and compared by unpaired t-test. Categorical variables were expressed by number (n) and frequencies $(\%)$. The $\chi^{2}$-test was used to compare the proportions. A P value of $<0.05$ was considered statisticcally significant.

\section{Results}

Complications were; bleeding in one patient in Group A $(3.5 \%)$ and two patients in Group B (10.5\%); empyema
Table 1. Patient's characteristics.

\begin{tabular}{lccc}
\hline & $\begin{array}{c}\text { Group A } \\
\text { (n 28)\# }\end{array}$ & $\begin{array}{c}\text { Group B } \\
(\mathrm{n} \mathrm{19}) \#\end{array}$ & P Value\# \\
\hline Age & $42.9( \pm 11.2) \#$ & $44.8( \pm 9.8)$ & \\
Sex & & & \\
Male & $15(53.5 \%)$ & $11(57.8 \%)$ & 0.76 \\
Female & $13(46.4 \%)$ & $8(42.1 \%)$ & \\
Lesions & & & \\
TB Bronchiectasis & $5(17.8 \%)$ & $3(15.7 \%)$ & 0.83 \\
Post TB Aspergilloma & $8(28.5 \%)$ & $5(26.3 \%)$ & 0.86 \\
TB Destroyed Lung & $6(21.4 \%)$ & $8(42.1 \%)$ & 0.12 \\
TB Cavity & $9(32.1 \%)$ & $3(15.7 \%)$ & 0.31 \\
Active TB( Drug Resistance) & $2(7.1 \%)$ & $2(10.5 \%)$ & 0.9 \\
Pneumonectomy & & & \\
Right & $18(64.2 \%)$ & $11(57.8 \%)$ & 0.65 \\
Left & $10(35.7 \%)$ & $8(42.1 \%)$ & \\
Diabetes Mellitus \# & $5(17.8 \%)$ & $4(21.0 \%)$ & $0.91 \#$ \\
Steroid Therapy\# & $8(28.5 \%)$ & $4(21.0 \%)$ & $0.81 \#$ \\
Renal Dysfunction\# & $1(3.5 \%)$ & 0 & $0.84 \#$ \\
Liver Dysfunction\# & $1(3.5 \%) \#$ & $1(5.2 \%)$ & $0.64 \#$ \\
\hline
\end{tabular}

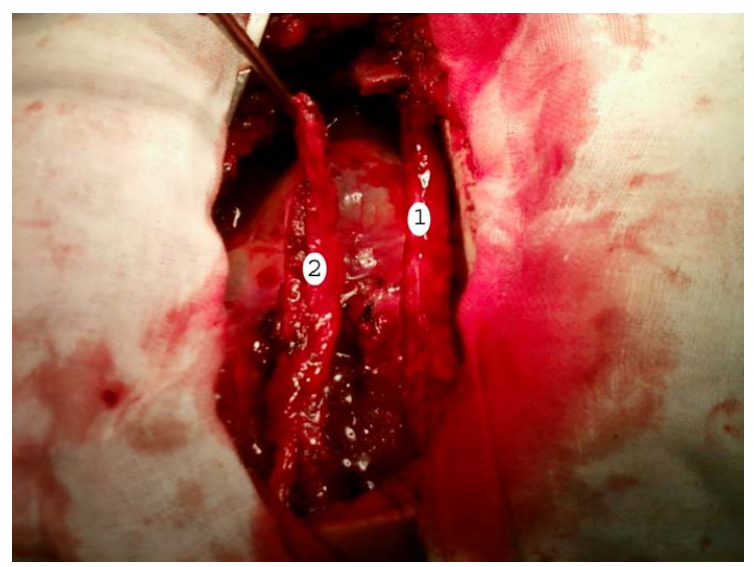

Figure 1. Shows pedicled intercostals muscle flap: No. 1 is the intercostals muscle harvested and cut at its posterior end; No. 2 is the intercostals muscle harvested and cut at its anterior end.

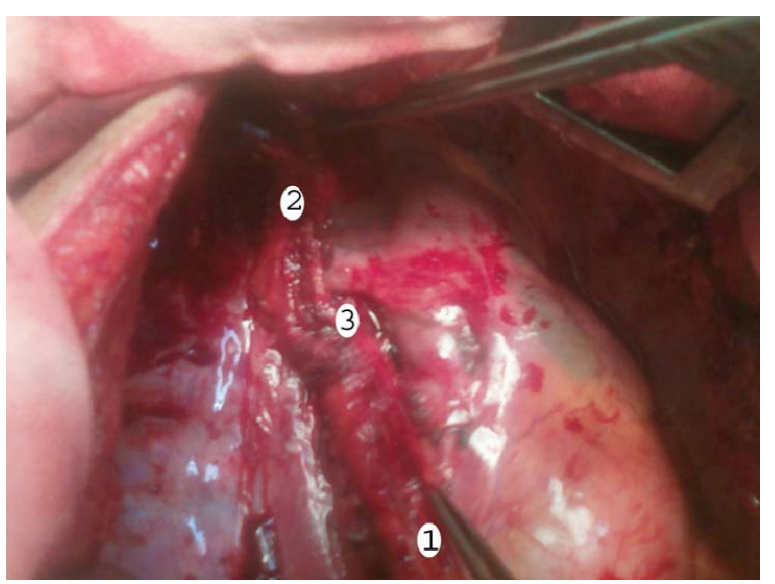

Figure 2. Shows intercostals muscle flaps: No. 1 and No. 2 implanted and sutured at both edges of bronchial stump No. 3 . 
in two patients (7.1\%) in Group A only one of them developed bronchopleural fistula; arrhythmias in one patient $(3.5 \%)$ in Group A and one patient in Group B (5.2\%); chylothorax in one patient $(3.5 \%)$ in Group A; while Chronic chest pain in one patient in Group A (3.5\%) and two patients in Group B (10.5\%) and bronchopleural fistula (BPF) in one patient in Group A (3.5\%), which developed three weeks after surgery and managed by exclusion of the bronchopleural fistula by bronchial stent applied between the trachea and left main bronchus, no (BPF) in Group B (Table 2). The postsurgical complications did not differ significantly between the two groups. The risk factors in patient with bronchopleural fistula were diabetes mellitus and drug resistance (active TB). The mean follow up period was $32.7 \pm 12.9$ months (range between 3 and 48 months). All patients remained symptoms free with no evidence of late bronchopleural fistula in Group B.

\section{Discussion}

The incidence of bronchopleural fistula after pulmonary resection is $1.2 \%-4.4 \%$ [1,3,7-9]. Pulmonary resection for chronic infection remains a common procedure in the Middle East [4] and Tuberculosis continues to account for the majority of these cases [5]. Pneumonectomy for inflammatory lung disease has been considered a highrisk procedure and several authors have concluded that the procedure should be avoided whenever possible [10]. The effective use of an intercostal muscle flap to close bronchopleural fistula after pneumonectomy with pedicled intercostals muscle flaps has been reported [11]. We thought to introduce a new technique as a prophylactic method to decrease the incidence of bronchopleural fistula after pneumonectomy in tuberculous patients by adding two pedicled intercostal muscle flaps on the bronchial stump with dual blood supply instead of using one pedicled intercostal muscle flap with single blood supply and follow up of our patients to detect the possible complications especially post-operative bronchopleural fistula. Operative mortality of pneumonectomy for inflammatory lung disease is relatively low $(0 \%$ - 2.4\%) [4-12] in our study, there was no surgical mortality. No complications during harvesting the intercostal muscle flaps. Surgical treatment was indicated for cases with drug resistance (active TB), four patients in both groups $(8.5 \%)$ were encountered with resistant or to symptomatic patients with destroyed lungs. Other indications for surgery included hemoptysis, aspergilloma and TB bronchiectasis. The pre-operative assessment of those patients should also confirm a healthy contra lateral lung with satisfactory function. We have closed all our bronchial stumps using interrupted vicryl sutures and covered with two pedicled intercostal muscle flaps in Group B and single pedicled muscle flap in Group A. we recog-
Table 2. Postoperative complications.

\begin{tabular}{cccr}
\hline & Group A (n 28) & Group B (n 19)\# & P Value\# \\
\hline Bronchopleural Fistula\# & $1(3.5 \%) \#$ & $0 \#$ & $0.84 \#$ \\
Empyema\# & $2(7.1 \%) \#$ & $0 \#$ & $0.64 \#$ \\
Chylothorax\# & $1(3.5 \%) \#$ & $0 \#$ & $0.84 \#$ \\
Chronic Chest Pain\# & $1(3.5 \%) \#$ & $2(10.5 \%) \#$ & $0.72 \#$ \\
Arrhythmia\# & $1(3.5 \%) \#$ & $1(5.2 \%) \#$ & $0.64 \#$ \\
Bleeding\# & $1(3.5 \%) \#$ & $2(10.5 \%) \#$ & $0.72 \#$ \\
\hline
\end{tabular}

nized one case of bronchopleural fistula in Group A (3.5\%) while no bronchopleural fistula in Group B, so we believe that if we used two pedicled intercostal muscle flaps with dual blood supply from anterior and posterior intercostal vessels as a prophylactic technique from postoperative BPF should be considered in all cases with post tuberculous pneumonectomy, specially when patients with MTB associated with other risk factors like renal failure, steroid therapy or diabetes mellitus. In our series we harvest the intercostal muscle by using blunt dissection and cautery and we found postoperative bleeding in one case in Group A and two cases in Group B which was statistically insignificant and treated by blood transfusion. There are few reports on the relationship between blood loss during surgery and chest-tube volume after surgery involving harvesting the intercostal muscle flap which considered a disadvantage of the procedure [13], but we found no increase in chest-tube volume associated with harvesting of single or double intercostal muscle flaps, probably because we don't used sharp dissection and harvesting was performed by blunt dissection and meticulous cautery, and the cases needed blood transfusion during surgery were the cases of aspergilloma which already associated with dense adhesion, as previous reports mentioned in cases of aspergilloma every effort should be made toward meticulous hemostasis, to avoid extrapleural approach and usually electrocautery for adhesion lysis is used to reduce incidence of bleeding [14]. Follow up of all patients after surgery in outpatient clinic for BPF was done, there is no BPF in Group B.

\section{Conclusion}

We conclude that double pedicled intercostal muscles flaps with dual blood supply buttressing the bronchial stump is a protective technique from bronchopleural fistula after pneumonectomy for pulmonary tuberculous lesions especially in cases with high risk factors.

\section{REFERENCES}

[1] H. Asamura, T. Naruke, R. Tsuchiya, T. Goya, H. Kondo and K. Suemasu, "Bronchopleural Fistulas Associated with Lung Cancer Operations. Univariate and Multivariate Analysis of Risk Factors, Management, and Outcome," Journal of Thoracic and Cardiovascular Surgery, Vol. 104, No. 5, 
1992, pp. 1456-1464.

[2] W. C. Fowler, C. J. Langer, W. J. Curran Jr. and S. M. Keller, "Postoperative Complications after Combined NeoAdjuvant Treatment of Lung Cancer," Annals of Thoracic Surgery, Vol. 55, No. 4, 1993, pp. 986-989. doi:10.1016/0003-4975(93)90131-Z

[3] M. Sonobe, M. Nakagawa, Ichinose M, Ikegami N, M. Nagasawa and T. Shindo, "Analysis of Risk Factors in Bronchopleural Fistula after Pulmonary Resection for Primary Lung Cancer," European Journal Cardio-Thoracic Surgery, Vol. 18, No. 5, 2000, pp. 519-523. doi:10.1016/S1010-7940(00)00541-8

[4] M. Ashour, "Pneumonectomy for Tuberculosis," European Journal Cardio-Thoracic Surgery, Vol. 12, No. 2 1997, pp. 209-213. doi:10.1016/S1010-7940(97)00155-3

[5] L. Eidus, A. G. Jessamin, E. S. Hershfield and D. M. Hellbecque, "A National Study to Determine the Prevalence of Drug Resistance in Newly Discovered Previously Untreated Cases," Canadian Journal of Public Health, Vol. 69, No. 2, 1978, pp. 146-153.

[6] M. D. Iseman, L. Madsen, M. Goble and M. Pomerantz, "Surgical Intervention in the Treatment of Pulmonary Disease Caused by Drug-Resistant Mycobacterium Tuberculosis," American Review of Respiratory Disease, Vol. 141 , No. 3, 1990, pp. 623-625. doi:10.1164/ajrccm/141.3.623

[7] D. Lardinois, A. Horsch, T. Krueger, M. Dusmet and H. Ris, "Mediastinal Reinforcement after Induction Therapy and Pneumonectomy: Comparison of Intercostals Muscle Versus Diaphragm Flaps," European Journal Cardio-Thoracic Surgery, Vol. 21, No. 1, 2002, pp. 74-78. doi:10.1016/S1010-7940(01)01079-X

[8] H. Sirbu, T. Busch, I. Aleksic, W. Schreiner, O. Oster and H. Dalichau, "Bronchopleural Fistula in the Surgery of Non-Small Cell Lung Cancer: Incidence, Risk Factors, and
Management," Annals of Thoracic and Cardiovascular Surgery, Vol. 7, No. 6, 2001, pp. 330-336.

[9] C. D. Wright, J. C. Wain, D. J. Mathisen and H. C. Grillo, "Postpneumonectomy Bronchopleural Fistula after Sutured Bronchial Closure: Incidence, Risk Factors, and Management," Journal of Thoracic and Cardiovascular Surgery, Vol. 112, No. 5, 1996, pp. 1367-1371. doi:10.1016/S0022-5223(96)70153-8

[10] G. Massard, A. Dabbagh, J. M. Wihlm, R. Kessler, P. Barsotti, N. Roeslin and G. Morand, "Pneumonectomy for Chronic Infection Is a High-Risk Procedure," Annals of Thoracic Surgery, Vol. 62, No. 4, 1996, pp. 1033-1037. doi:10.1016/0003-4975(96)00596-6

[11] P. H. Hollaus, M. Huber, F. Lax, N. Peter, W. Bohm and S. P. Nestor, "Closure of Bronchopleural Fistula after Pneumonectomy with a Pedicled Intercostals Muscle Flap," European Journal Cardio-Thoracic Surgery, Vol. 16, No. 2, 1999, pp. 181-186. doi:10.1016/S1010-7940(99)00164-5

[12] S. Halezeroglu, M. Keles, A. Uysal, M. Celik, C. Senol, G. Haciibrahimoglu and B. Arman, "Factors Affecting Postoperative Morbidity and Mortality in Destroyed Lung," Annals of Thoracic Surgery, Vol. 64, No. 6, 1997, pp. 16351638. doi:10.1016/S0003-4975(97)00999-5

[13] T. Maniwa, Y. Saito, H. Kaneda and H. Imamura, "Bronchial Stump Reinforcement with the Intercostal Muscle Flap without Adverse Effects," European Journal CardioThoracic Surgery, Vol. 30, No. 4, 2006, pp. 652-656. doi:10.1016/i.ejcts.2006.07.023

[14] A. Brik, A. Salem, A. Kamal, M. Abdel-Sadek, M. Essa, M. El Sharawy, A. Deebes and K. A. Bary, "Surgical Outcome of Pulmonary Aspergilloma," European Journal CardioThoracic Surgery, Vol. 34, No. 4, 2008, pp. 882-885. doi:10.1016/j.ejcts.2008.06.049 